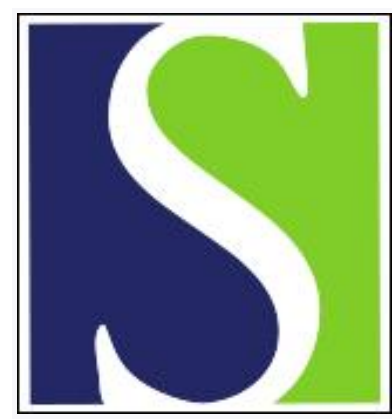

Scand J Work Environ Health 2019;45(5):450-457

https://doi.org/10.5271/sjweh.3810

Published online: 03 Mar 2019, Issue date: 01 Sep 2019

Self-reported skin problems and the healthy worker effect in the general working population of Norway: a three-year prospective study

by Alfonso $\mathrm{JH}$, Johannessen $\mathrm{HA}$

Given that self-reported skin problems at baseline consistently predicted job loss due to health problems at follow-up, efforts are needed to prevent job loss among these workers. Future population-based prospective studies assessing associations between skin exposures and skin problems should take into account the impact of a potential healthy worker effect.

Affiliation: Department of Occupational Medicine and Epidemiology, National Institute of Occupational Health, Pb 8149 Dep N-0033 Oslo, Norway. jose.alfonso@stami.no

Refers to the following texts of the Journal: 1995;21(1):30-35 2005;31(6):474-478

Key terms: dermatitis; eczema; healthy worker effect; Norway; occupational dermatology; occupational skin exposure; prospective study; self report; skin; skin condition; skin problem

This article in PubMed: www.ncbi.nlm.nih.gov/pubmed/30826843 


\title{
Self-reported skin problems and the healthy worker effect in the general working population of Norway: a three-year prospective study
}

\author{
by Jose H Alfonso, MD, PhD, ${ }^{1}$ Håkon A Johannessen, $P h D^{2}$
}

\begin{abstract}
Alfonso JH, Johannessen HA. Self-reported skin problems and the healthy worker effect in the general working population of Norway: a three-year prospective study. Scand J Work Environ Health. 2019:45(5):450-457. doi:10.5271/sjweh.3810
\end{abstract}

Objectives This study aimed to assess whether the occurrence of skin problems in 2006 (baseline) was associated with response frequency, quitting a job due to health problems, and change in occupational skin exposures in 2009.

\begin{abstract}
Methods We conducted a three-year prospective study of the general working population of Norway. Associations between baseline indicators (sex, age, education, occupation), and occurrence of skin problems with response frequency at follow-up were assessed with Chi-square test and unconditional logistic regression. Associations between the occurrence of skin problems at baseline with quitting a job due to health problems and skin exposure at follow-up were also assessed with unconditional logistic regression.
\end{abstract}

Results We found no evidence of an association between the occurrence of skin problems at baseline and a lower response frequency at follow-up. Age, sex, education, and occupation were the most important predictors for response at follow-up. Skin problems at baseline consistently predicted quitting a job due to health problems at follow-up. No evidence of change in the patterns of occupational skin exposures at follow up in 2009 was found for workers reporting skin problems in 2006.

Conclusions While skin problems at baseline were not related to a lower response frequency at follow-up, our results suggest that workers reporting skin problems may quit their jobs due to health problems. Preventive efforts are still needed to reduce hazardous occupational skin exposures among workers reporting skin problems.

Key terms dermatitis; eczema; occupational dermatology; occupational skin exposure; self-report; skin condition.

Population-based prospective studies focusing on skin problems due to occupational skin exposures are scarce but highly needed to assess the epidemiology of workrelated skin diseases. In a three-year prospective study of the general working population of Norway, we previously reported evidence of an association between self-reported occupational skin exposure and skin problems (1). However, such an association was weaker for responders reporting skin exposure at baseline (2006) only, compared to those reporting exposure at follow-up only (2009), and at both baseline and follow-up.

Healthy worker survivor effect is a phenomenon in which workers with health problems are more likely than healthy coworkers to leave high-exposure jobs, either by ending employment or being transferred (2). This selection away from exposed jobs may reduce the impact of skin exposure on a given person, but on the other hand it may lead to the biased conclusion that the occupational skin exposure is not associated with skin problems.

First, the occurrence of skin problems at baseline could have influenced an eventual loss to follow-up. Whilst different mechanisms of loss to follow-up have been described, the most problematic occurs if dropouts are related to the outcome of the study leading to an underestimation of the association between occupational skin exposure and skin problems (attrition bias) $(3,4)$.

Second, the occurrence of skin problems at baseline could have led to changes in patterns of skin exposure at follow-up (for example, avoidance of hazardous exposure at work, implementation of preventive measures, or both).

1 Department of Occupational Medicine and Epidemiology, National Institute of Occupational Health, Oslo, Norway.

2 Department of National Work Environment Surveillance, National Institute of Occupational Health, Oslo, Norway.

Correspondence to: Jose Hernán Alfonso, Department of Occupational Medicine and Epidemiology, National Institute of Occupational Health, Pb 8149 Dep N-0033 Oslo, Norway. [E-mail: jose.alfonso@stami.no] 
We sought, therefore, to (i) assess whether a potential healthy worker survivor effect have an impact on the response frequency at follow-up and (ii) examine whether the occurrence of skin problems at baseline predicts quitting a job due to health problems and changes in patterns of self-reported skin exposure at follow-up.

\section{Methods}

\section{Study design and population}

This three-year prospective study comprised a random sample of the general working population of Norway taken from the Survey of Level of Living-Working Conditions (Statistics Norway) 2006 and 2009. Only originally identified members are followed-up to the end of study period. Table 1 shows details of this survey $(5,6)$.

\section{Eligibility}

Eligible responders included Norwegian residents aged 18-69 years (66 years in 2006), covering the general working age population. In 2006, the source population consisted of 2941281 persons. A gross sample of 18679 individuals, independent of employment status, was randomly drawn from this group, and 12550 (67\%) persons were then interviewed. Of these, 9961 were enrolled in paid work in 2006. In 2009 the source population consisted of 3079157 persons. A gross sample of 20136 individuals, independent of employment status, was randomly drawn from this population, of which 7 881 did not respond at baseline. The interviewer was unable to reach $19 \%$ of respondents despite several attempts, $16 \%$ did not want to participate, and 3\% were unable to participate. A total of 12255 (61\%) persons were then interviewed (table 1, figure 1).

\section{Panel data for statistical analysis}

The panel data comprised responders participating in both surveys, totalling 9375 persons (response frequency: $50.2 \%$ of the gross and $74.4 \%$ of the baseline cross-sectional sample). Responders who were enrolled in paid work at baseline ( $\mathrm{N}=9961)$ constituted the study population for attrition analyses (figure 1). Responders in the panel dataset at baseline and follow-up who were enrolled in paid work at baseline comprised the study population of those quitting a job due to health problems in 2009 ( $\mathrm{N}=7559)$. Responders in the panel sample who were enrolled in paid work at both baseline and follow-up constituted the population for self-reported patterns of skin exposure at follow-up $(\mathrm{N}=6745)$.
Table 1. Survey a of Level of Living/Working Conditions 2006 and 2009: details of the population (Statistics Norway).

\begin{tabular}{lrr}
\hline & \multicolumn{1}{c}{2006} & \multicolumn{1}{c}{2009} \\
\cline { 2 - 3 } Source population & 2941281 & 3079157 \\
Randomly drawn sample & 18999 & 20460 \\
Age (years) & $18-66$ & $18-69$ \\
(Death, resident abroad/or institution) & 320 & 324 \\
Gross sample & 18679 & 20136 \\
Responders & 12550 & 12555 \\
No-responders & 6128 & 7881 \\
Response frequency (\%) & 67.2 & 61.0 \\
Data collection (dates) & $18 / 09 / 2006$ & $22 / 06 / 2009$ \\
& $-24 / 02 / 2007$ & $-9 / 01 / 2010$ \\
\hline
\end{tabular}

a Method for data collection: computer-assisted telephone interviews, with the exception of $0.5 \%$, which were computer-assisted personal interviews.

\section{Demographic variables}

Sex and age were based on data from the National Registry of Norway. Responders are grouped by age at year-end for the completion of the interview.

Education was based on information from Survey Data from Statistics Norway. Occupation was based on information from an open questionnaire, coded by Statistics Norway into a professional title in accordance with the International Standard Classification of Occupations (ISCO 1988) and recoded into ten major occupational groups (legislators, senior officials, and managers; professionals; technicians and associate professionals; clerks; service workers and shop sale workers; skilled agricultural and fishery workers; craft-related trade workers; plant-machine operators and assemblers; elementary occupations; and other occupations).

\section{Exposure variables}

The one-month prevalence of skin problems at baseline (2006) was measured with a single question: "Have you over the past month been afflicted by eczema, itchy skin, or rash?". Those responding yes were further asked: "Have you been severely afflicted, somewhat afflicted, or little afflicted?" Cases were defined as responders who reported being afflicted a little or more.

\section{Outcome variables}

Quitting a job due to health problems in 2009 was measured with a single question: "What was the main reason why you quit your previous job?", with 14 possible responses. Cases were defined as responders answering: "Because of own health problems/disease".

Occupational skin exposure at follow-up (water, cleaning products, oil and cutting fluids, indoor dry air, cold, warm, organic/mineral or metal dust) was assessed based on nine items developed by an expert group for a Nordic cooperation project. Details of these questions are described elsewhere (1). 


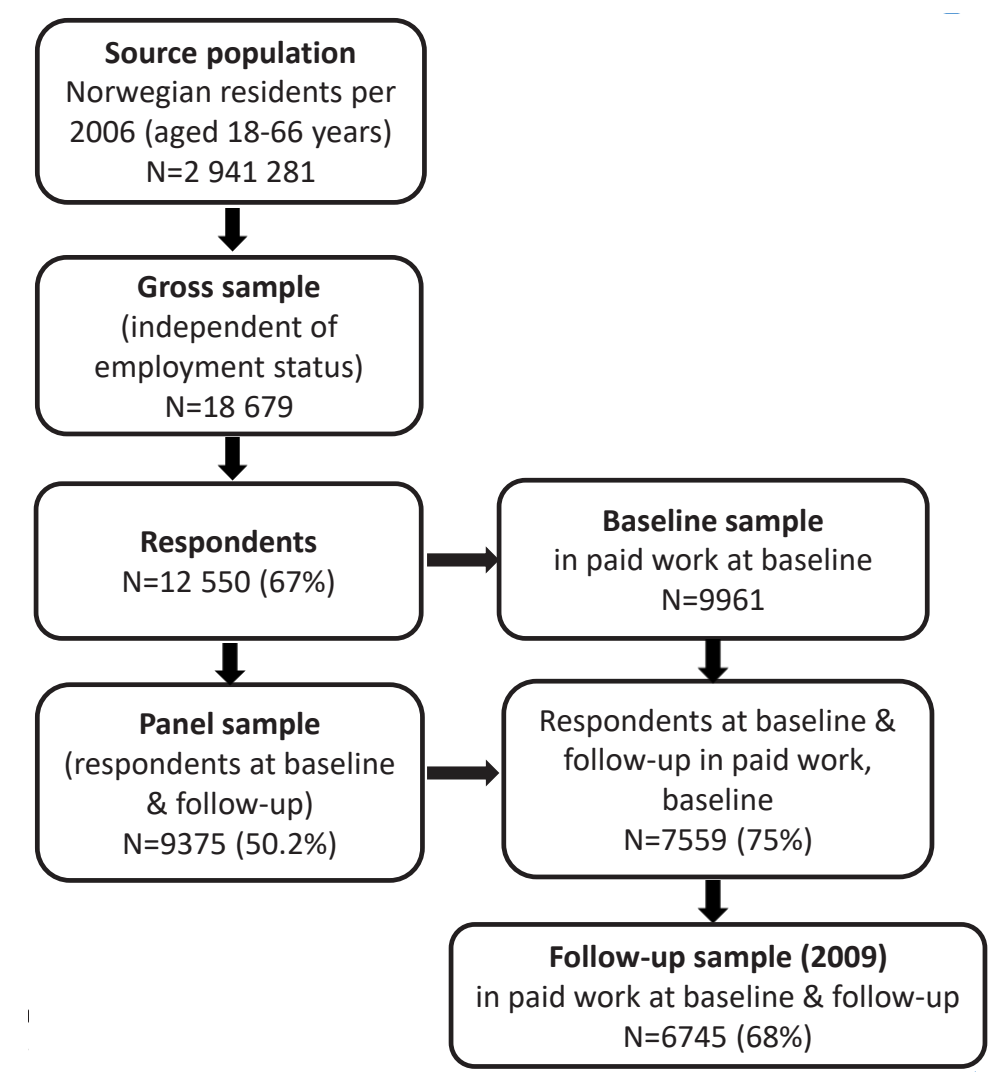

Figure 1. Population sample at baseline (2006)and follow-up (2009). Survey of Level of Living-Working Conditions, Statistics Norway.

\section{Statistical analysis}

Attrition analyses were performed to assess whether a potential healthy worker effect influenced the response frequency at follow-up. Associations between baseline indicators (sex, age, education, occupation, and occurrence of skin problems) with response frequency at follow-up were assessed by Pearson's Chi-square tests and unconditional logistic regression. The level for significance was set to $\mathrm{P}<0.05$ [95\% confidence interval (CI)].

The association between the occurrence of skin problems in 2006 and quitting a job due to health problems in 2009 was assessed with unconditional logistic regression. Adjustments were made for baseline predictors of response frequency at follow-up and psychological distress as well as musculoskeletal pain, which are the most frequent health problems resulting in sick leave in Norway $(7,8)$.

Psychological distress was measured with two questions: "Have you during the past month been very bothered, quite bothered, slightly bothered, or not bothered by dejection or depression?" and "Have you during the past month been very bothered, quite bothered, slightly bothered, or not bothered by nervousness, anxiety, or restlessness?" Psychological distress was dichotomized as being slightly or more bothered on either of the two questions.
Musculoskeletal pain was measured with two questions: "Have you, over the past month, been severely afflicted by, somewhat afflicted by, a little afflicted by, or not afflicted at all by pain in your neck and/or shoulders?" and "Have you, over the past month, been severely afflicted by, somewhat afflicted by, a little afflicted by, or not afflicted at all by pain in your lower back?" Musculoskeletal pain was defined as respondents who reported being severely or somewhat afflicted on either of the two questions.

To assess whether skin problems at baseline could have led to changes in exposure patterns at follow-up, we further analyzed associations between skin problems at baseline and occupational skin exposures at followup by unconditional logistic regression. Associations were estimated as odds ratios (OR) with 95\% CI. Data analyses were performed with the Statistical Package for Social Sciences version 16.0 for Windows (SPSS Inc, Chicago, IL, USA).

\section{Ethical considerations}

Statistics Norway carried out the survey according to statutory rules. Statistics Norway has appointed its own privacy ombudsman, approved by the Norwegian Data Inspectorate. All persons gave their informed consent prior to their inclusion in the study. 
Data has been prepared and made available and anonymized by NSD (Norwegian Center for Research Data AS). Neither Statistics Norway nor NSD are responsible for the analysis or the interpretations made here.

\section{Results}

The occurrence of skin problems did not predict response frequency at follow-up. Sex, age, education, and occupation were the most important predictors (table 2). Elementary occupations had double the OR of not responding at follow-up. The response frequency was higher for women and increased by age and higher level of education. Table 3 shows that self-reported skin problems in 2006 was a consistent predictor of quitting a job in 2009 due to health problems after adjusting for variables predicting response frequency at follow-up (model 1) and for self-reported psychological distress and musculoskeletal pain (model 2). Table 4 shows no evidence of a decreased OR of skin exposure at follow up among employees with skin problems at baseline. On the other hand, the occurrence of self-reported skin problems at baseline was associated with an increased OR of occupational skin exposure to cleaning products and mineral dust at follow-up.

\section{Discussion}

Contrary to our expectations, self-reported skin problems at baseline predicted neither response frequency nor avoidance of occupational hazardous skin exposures at follow-up. Nevertheless, self-reported skin problems at baseline consistently predicted quitting a job due to health problems at follow up. Increased likelihood of

Table 2. Response frequency at baseline (2006) and follow-up (2009) and group difference at baseline and follow-up for demographic variables and self-reported skin problems. [OR=odds ratio; $\mathrm{Cl}=$ confidence interval.]

\begin{tabular}{|c|c|c|c|c|}
\hline Baseline predictors & $\begin{array}{c}\text { Responders at } \\
\text { baseline (N) }\end{array}$ & $\begin{array}{l}\text { Response frequency } \\
\text { at follow-up (\%) }\end{array}$ & $\begin{array}{c}\text { Group difference } \\
\text { Response frequency }\left(\chi^{2}\right)\end{array}$ & Crude OR $(95 \% \mathrm{Cl})$ \\
\hline \multicolumn{5}{|l|}{ Sex } \\
\hline Male & 5236 & $3916(74.8)$ & \multirow[t]{2}{*}{$7.006(P=0.008)$} & (Ref) \\
\hline Female & 4725 & $3643(77.1)$ & & $0.88(0.80-0.97)$ \\
\hline \multicolumn{5}{|l|}{ Age (years) } \\
\hline $17-24$ & 987 & $581(58.9)$ & \multirow[t]{5}{*}{$231.390(P=0.000)$} & (Ref) \\
\hline $25-34$ & 2003 & $1418(70.8)$ & & $0.59(0.50-0.69)$ \\
\hline $35-44$ & 2655 & $2100(79.1)$ & & $0.38(0.32-0.44)$ \\
\hline $45-54$ & 2412 & 1900 (78.8) & & $0.38(0.33-0.45)$ \\
\hline $55-66$ & 1904 & 1557 (81.8) & & $0.31(0.26-0.37)$ \\
\hline \multicolumn{5}{|l|}{ Education } \\
\hline Basic school level & 683 & $464(67.9)$ & \multirow{5}{*}{$171.234(P=0.000)$} & (Ref) \\
\hline Upper secondary education, not finished & 2385 & $1681(70.5)$ & & $0.89(0.74-1.07)$ \\
\hline Upper secondary education & 3132 & $2343(74.8)$ & & $0.71(0.56-0.85)$ \\
\hline University/college 4 years & 2701 & $2234(82.7)$ & & $0.44(0.37-0.53)$ \\
\hline University/college $\geq 4$ years & 880 & $742(84.3)$ & & $0.39(0.30-0.50)$ \\
\hline \multicolumn{5}{|l|}{ Occupation } \\
\hline Legislators, senior officials and managers & 952 & $740(77.7)$ & \multirow[t]{10}{*}{$200.310(P=0.000)$} & (Ref) \\
\hline Professionals & 1411 & 1156 (81.9) & & $0.77(0.63-0.95)$ \\
\hline Technicians and associate professionals & 2547 & $2081(81.7)$ & & $0.78(0.65-0.94)$ \\
\hline Clerks & 646 & $492(76.2)$ & & $1.09(0.86-1.38)$ \\
\hline Service workers and shop sale workers & 2026 & $1444(71.3)$ & & $1.40(1.17-1.68)$ \\
\hline Skilled agricultural and fishery workers & 220 & $183(83.2)$ & & $0.71(0.48-1.04)$ \\
\hline Craft-related trade workers & 1002 & $711(71.0)$ & & $1.43(1.16-1.75)$ \\
\hline Plant-machine operators and assemblers & 642 & $419(65.3)$ & & $1.86(1.49-2.32)$ \\
\hline Elementary occupations & 343 & $211(61.5)$ & & $2.18(1.67-2.85)$ \\
\hline Other occupations & 170 & $121(71.2)$ & & $1.41(0.98-2.04)$ \\
\hline \multicolumn{5}{|c|}{ Skin problems (eczema, itchy skin or rash in the last month) } \\
\hline No & 8643 & $6569(76.0)$ & \multirow[t]{2}{*}{$0.182(P=0.670)$} & (Ref) \\
\hline Yes & 1311 & $988(75.4)$ & & $1.03(0.90-1.18)$ \\
\hline
\end{tabular}

Table 3. Association between self-reported skin problems at baseline (2006) and quitting a job due to health problems in 2009.

\begin{tabular}{lrcrr}
\hline & Total & $\begin{array}{c}\text { Quite job in 2009 due to } \\
\text { health problems [N (\%)] }\end{array}$ & $\begin{array}{c}\text { Crude odds ratio } \\
(95 \% \mathrm{Cl})\end{array}$ & $\begin{array}{c}\text { Model 1 a odds ratio } \\
(95 \% \mathrm{Cl})\end{array}$ \\
\cline { 2 - 5 } Skin problems in 2006 & & & & $\begin{array}{c}\text { Model 2 }{ }^{\mathrm{b}} \text { odds ratio } \\
(95 \% \mathrm{Cl})\end{array}$ \\
No & 6563 & $149(2.3 \%)$ & 1 (ref.) & 1 (ref) \\
Yes & 989 & $42(4.2 \%)$ & $1.9(1.3-2.7)$ & $1.7(1.2-2.5)$ \\
\hline
\end{tabular}

adjusted for occupation, sex, education, and age.

${ }^{\text {b } F u r t h e r ~ a d j u s t e d ~ f o r ~ s e l f-r e p o r t e d ~ p s y c h o l o g i c a l ~ d i s t r e s s ~ a n d ~ m u s c u l o s k e l e t a l ~ p a i n ~ i n ~} 2006$. 
Table 4. Association between self-reported skin problems at baseline (2006) and self-reported skin exposure at follow-up (2009)

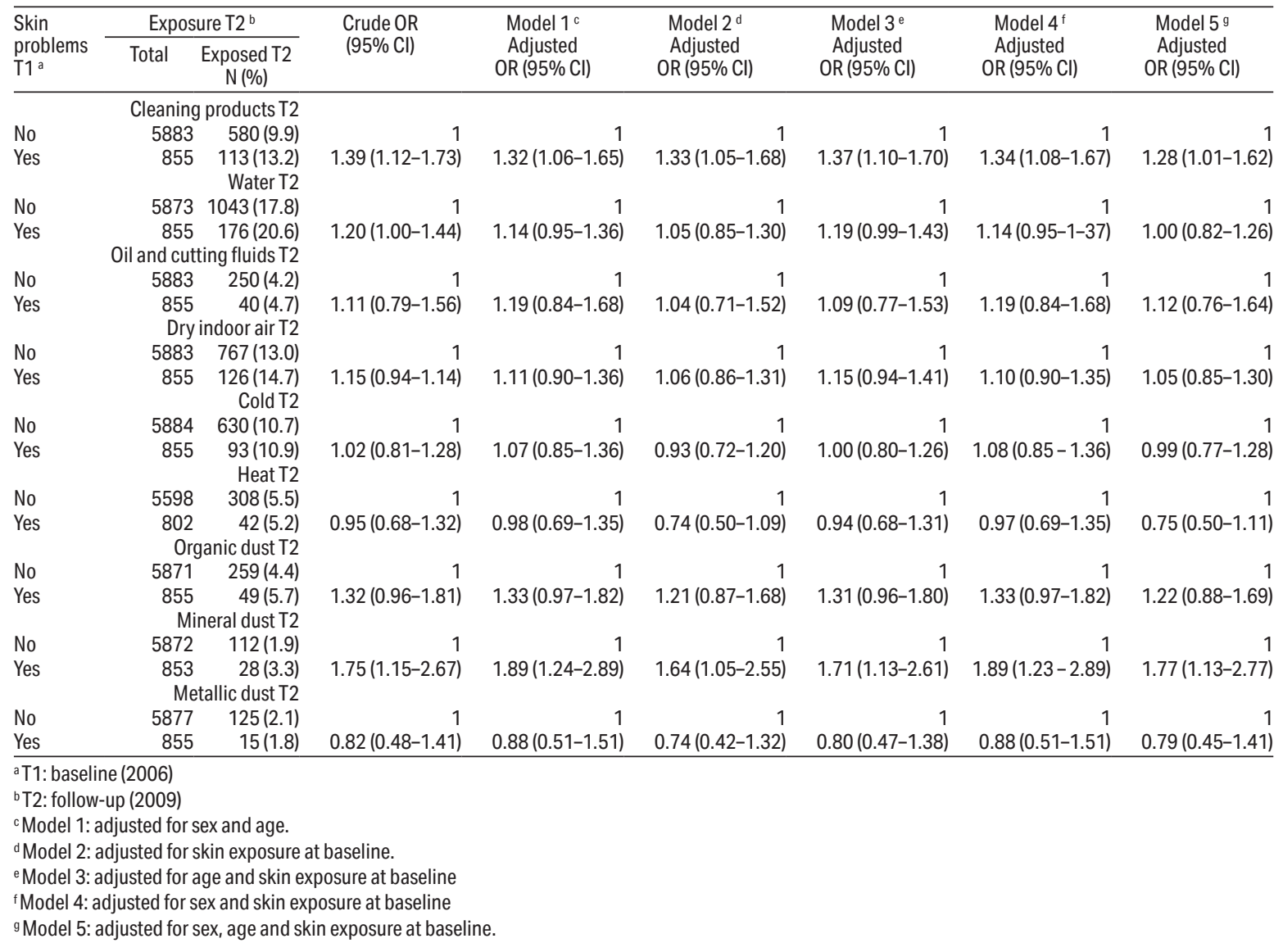

subsequent quitting a job among respondents with skin problems at baseline represents evidence of a healthy worker survivor effect, which may have weakened the associations between occupational skin exposure and skin problems previously reported (1).

The consistent association between skin problems at baseline and quitting a job due to health problems at follow-up is of great concern and has not yet been reported for the general working population of Norway. This finding is in line with our previous report of an association between certain occupational skin exposures and long-term sick leave in the same working population (9). Moreover, we hypothesized that many of these workers may be not only on sick leave, but also close to disability retirement due to the end of the maximum period for sickness absence benefit (one year). For instance, according to Norwegian population-based registry data workers in wet work and service occupations have the highest occurrence of sick leave due to contact dermatitis and are at the end of their maximum period for sickness absence benefit due to the same diagnosis (10). This finding highlights the need to help workers avoid taking sick leave and quitting a job due to skin problems. Furthermore, future prospective studies assessing an association between occupational skin exposure and skin problems should be aware of a potential underestimation of the risk estimates due to the healthy worker effect.

Our findings do not support the initial hypothesis that workers with skin problems at baseline avoid skin hazardous exposures at follow-up. For instance, skin exposure to cleaning products and mineral dust at follow-up was more likely to occur among participants reporting skin problems at baseline. Moreover, low or nonsignificant OR were found for the other skin hazardous exposures. Given that avoidance of hazardous exposures leading to work-related skin problems is a minimum standard for effective prevention of work-related and occupational skin diseases (11), our findings suggest that additional preventive initiatives are still needed to reduce hazardous occupational skin exposures in workers suffering from skin problems. It should also be kept in mind that the association between skin problems at baseline with skin exposure at follow-up may be partly mediated by skin exposure at baseline, whereby our adjusted estimates of models $2-5$ in table 4 may represent a slight underestimation of the true associations.

In questionnaire-based studies, non-response may introduce selection bias already at baseline. While the 
non-response frequency at baseline was $33 \%$, Statistics Norway did not find systematic differences across the benchmarks of age, sex, and region between responders and non-responders $(5,6)$. Although the study design and the outcome measure are not wholly comparable, Meding et al (12) found no statistical difference with regard to the one-year prevalence of hand dermatitis between responders and drop-outs in a Swedish population-based study. Moreover, it should be remarked that our findings do not exclude a plausible healthy worker hire effect (healthy worker effect before recruitment) as this study included a random sample of the general population at work (1). Firstly, workers with chronic skin conditions, such as severe contact dermatitis (13) or psoriasis (14), may have been less likely to respond at baseline. Secondly, for some workers, individual susceptibility factors, such as atopic dermatitis, could have led them to avoid occupations with hazardous skin exposures. For example, Holm \& Veierød (13) reported that the occurrence of atopic dermatitis was $50 \%$ lower among Norwegian hairdressers compared to teachers. In addition, Bregnhøj et al (15) reported a lower incidence of hand dermatitis and fewer cases with atopic dermatitis among hairdressers apprentices than in a matched control group from the general population. More recently, Bandier et al (16) found that filaggrin mutation carriers [risk factor for irritant contact dermatitis (ICD)] who reported hand dermatitis before 15 years of age avoided occupational exposure to irritants. On the other hand, a German prospective cohort study (17) and a Swedish nested case-control study (18) (both population-based) did not find strong evidence of an association between atopic dermatitis and the subsequent choice of first job or avoidance of occupations with hazardous skin exposures. Prospective studies using a life-course perspective will be more suitable to assess the impact of healthy worker effect before recruitment.

\section{Strengths and limitations}

Briefly, the strengths of this study are the populationbased material drawn from a random sample of the Norwegian general working population, its prospective design, the response frequency of $67 \%$ at follow-up, and the focus on occupational skin exposure rather than occupational tittles (1).

The main limitations include the use of a non-validated survey to assess occupational exposures (1), however, the associations found between skin exposures and problems are consistent with the most frequent skin exposures leading to work-related skin diseases in Norway (1). As regards the validity of the question on skin problems in the last month, it is not completely true that this question is not validated. A cross-sectional population-based study among young adults (Oslo
Health Study) found an agreement of $85 \%$ between self-reported skin problems and expert assessment based on specific criteria. Although this study focused on the work-relatedness of self-reporting, the question used was the same as in this study. Moreover, the disagreement in the majority of the cases was because the responder did not consider the skin problems to be work-related (19). The fact that the question on skin problems did not include additional information on the anatomical location or type of skin condition should be interpreted in the light of self-experienced health and illness (20), where subclinical cases also may be included. For instance, considering the pathophysiology of some work-related skin conditions, the question on eczema, itchy skin, or rash during the last month may be prone to capture skin problems attributable to skin conditions with an acute and subacute onset such as chemical skin injury, contact urticaria, acute ICD, delayed acute ICD, irritant reactions, and sensory irritation. On the other hand, a three-year follow-up may capture skin problems attributable to slowly developing skin conditions such as chronic ICD, traumatic ICD, acneiform ICD, friction dermatitis, asteatotic irritant dermatitis, or worsening of atopic dermatitis or psoriasis due to occupational exposures. Additionally, we highlight that the aim of using panel data from the Survey on Working-Living Conditions is to conduct epidemiological surveillance of work environment conditions, thus a symptom-based question may have several advantages. Firstly, it facilitates the reporting of minor symptoms and consequently the identification of associations between occupational exposures and skin problems. Secondly, health perceptions measured by self-report may be more appropriate to the purposes of this study, given that the healthy worker survivor effect is supposed to be determined by conscious decisions (21) due to self-experienced health and illness. Finally, it has been suggested that, at least in the studied populations $(22,23)$, self-report is more likely to under- than overestimate the true prevalence of skin conditions.

Self-report of occupational skin exposure and skin conditions is widely used in occupational dermatology, as it is often one of the most feasible methods for collecting information at the population level (24). Teschke et al (25) noted in a systematic review that subjects can reliably and accurately report exposures to hazards which they can easily sense if the agents are presented in predefined questions regarding broad classes of exposure, for example "oil and greases", "degreasers" rather than about specific chemical exposures, for example, "chromium". Questions used by the Survey of LivingWorking conditions 2006 and 2009 to assess occupational exposures are examples of wording that included broad classes of exposure to agents that can easily be sensed by the skin. However, it should be acknowledged 
that self-reported data might be prone to information bias. For instance, those participants reporting skin problems could have recalled their skin exposures better than those not reporting skin problems. Thus, to reduce a potential overestimation due recall bias, we included adjustment for skin exposure at baseline in the assessment of associations between self-reported skin problems and self-reported skin exposure at follow-up. The order of the questioning in which questions on skin exposures were administrated before those on health problems with different types of response categories may have contributed to a reduction in the effect of common-method bias (26).

\section{Generalizability}

Sampling bias is not an issue in this study and the findings can be generalized to the general working population of Norway, as a random sample of the Norwegian general working population aged 18-69 years was included. Although the Survey of Living-Working Conditions does not include migrant workers on short-term contracts, by 2016, these workers constituted about 3\% of the working population in Norway (10).

\section{Concluding remarks}

Our results suggest that workers with skin problems in 2006 had a higher risk of quitting their job in 2009 due to health problems. Preventive efforts are needed to help workers avoiding having to quit a job due to health problems and, more generally, to reduce occupational hazardous skin exposures at work. Future population-based prospective studies in the field of occupational dermatology should assess the impact of a potential healthy worker effect when reporting associations between occupational exposures and skin conditions.

\section{Acknowledgments}

We thank Tore Tynes who contributed to the development of this manuscript. The results of table 2 have been presented as a poster in the $25^{\text {th }}$ EPICOH 2016 "Occupational Health: Think Globally, Act Locally", September 4-7, 2016, Barcelona, Spain.

The authors declare no conflicts of interest.

\section{References}

1. Alfonso JH, Thyssen JP, Tynes T, Mehlum IS, Johannessen HA. Self-reported occupational exposure to chemical and physical factors and risk of skin problems: a 3-year followup study of the general working population of Norway. Acta Derm Venereol 2015 Nov;95(8):959-62. https://doi. org/10.2340/00015555-2135

2. Shah D. Healthy worker effect phenomenon. Indian $J$ Occup Environ Med 2009 Aug;13(2):77-9. https://doi. org/10.4103/0019-5278.55123

3. Kristman V, Manno M, Côté P. Loss to follow-up in cohort studies: how much is too much? Eur J Epidemiol 2004;19(8):751-60. https://doi.org/10.1023/ B:EJEP.0000036568.02655.f8.

4. Nielsen MB, Knardahl S. The healthy worker effect: do health problems predict participation rates in, and the results of, a follow-up survey? Int Arch Occup Environ Health 2016 Feb;89(2):231-8. https://doi.org/10.1007/s00420-015-10666.

5. Norway S. [Survey of Living Conditions 2006- crosssectional study. Work environment.] Available from: http:// www.ssb.no/en/arbeid-og-lonn/statistikker/arbmiljo/ hvert-3-aar/2007-09-20? fane=om Statistics Norway, 2010 [Accessed: 13/10/2018] [In Norwegian].

6. Norway S. [Survey of Living Conditions 2009-cross-sectional study. Work environment.] Available from: http://www.ssb. no/a/publikasjoner/pdf/notat_201016/notat_201016.pdf. Statistics Norway 2010. p. 8-14. [In Norwegian]. [Accessed: $13 / 10 / 2018]$

7. Aagestad C, Johannessen HA, Tynes T, Gravseth HM, Sterud T. Work-related psychosocial risk factors for long-term sick leave: a prospective study of the general working population in Norway. J Occup Environ Med 2014 Aug;56(8):787-93. https://doi.org/10.1097/JOM.0000000000000212.

8. Sterud T, Johannessen HA. Do work-related mechanical and psychosocial factors contribute to the social gradient in long-term sick leave: a prospective study of the general working population in Norway. Scand J Public Health 2014 May;42(3):329-34. https://doi. org/10.1177/1403494814521506.

9. Alfonso JH, Tynes T, Thyssen JP, Holm JØ, Johannessen HA. Self-reported occupational skin exposure and risk of physician-certified long-term sick leave: a prospective study of the general working population of Norway. Acta Derm Venereol 2016 Mar;96(3):336-40. https://doi. org/10.2340/00015555-2253.

10. National Institute of Occupational Health. Faktabok om arbeidsmiljø og helse (2018). STAMI-rapport, årgang 19, nr. 3, Oslo: Statens arbeidsmiljøinstitutt. [Fact book on work environment and health].STAMI Available from: https:// stami.no/content/uploads/2018/06/Faktaboka-2018.pdf [In Norwegian]. [Accessed: 13/10/2018]

11. Alfonso JH, Bauer A, Bensefa-Colas L, Boman A, Bubas 
$\mathrm{M}$, Constandt $\mathrm{L}$ et al. Minimum standards on prevention, diagnosis and treatment of occupational and work-related skin diseases in Europe - position paper of the COST Action StanDerm (TD 1206). J Eur Acad Dermatol Venereol 2017 Jun;31 Suppl 4:31-43. https://doi.org/10.1111/jdv.14319.

12. Meding B, Swanbeck G. Prevalence of hand eczema in an industrial city. Br J Dermatol 1987 May;116(5):627-34. https://doi.org/10.1111/j.1365-2133.1987.tb05895.x.

13. Holm JØ, Veierød MB. An epidemiological study of hand eczema among hairdressers. Study I to VI. Acta Derm Venereol Suppl (Stockh) 1994;187:8-27.

14. Meding B, Wrangsjö K, Burdorf A, Järvholm B. Disability Pensions due to Skin Diseases: A Cohort Study in Swedish Construction Workers. Acta Derm Venereol 2016 Feb;96(2):232-6. https://doi.org/10.2340/00015555-2215.

15. Bregnhøj A, Søsted H, Menné T, Johansen JD. Healthy worker effect in hairdressing apprentices. Contact Dermat 2011 Feb;64(2):80-4. https://doi.org/10.1111/j.16000536.2010.01831.x.

16. Bandier J, Ross-Hansen K, Carlsen BC, Menné T, Linneberg A, Stender $\mathrm{S}$ et al. Carriers of filaggrin gene (FLG) mutations avoid professional exposure to irritants in adulthood. Contact Dermat 2013 Dec;69(6):355-62. https:// doi.org/10.1111/cod.12097.

17. Wei J, Gerlich J, Vogelberg C, von Mutius E, Windstetter $\mathrm{D}$, Genuneit $\mathrm{J}$ et al. Do young adults with atopic dermatitis avoid harmful workplace exposure at their first job? A prospective cohort study. Int Arch Occup Environ Health 2016 Apr;89(3):397-406. https://doi.org/10.1007/s00420015-1078-2.

18. Nyrén M, Lindberg M, Stenberg B, Svensson M, Svensson A, Meding B. Influence of childhood atopic dermatitis on future worklife. Scand J Work Environ Health 2005 Dec;31(6):474-8. https://doi.org/10.5271/sjweh.952.

19. Mehlum IS, Kjuus H, Veiersted KB, Wergeland E. How valid is self-reported work relatedness of health problems? A comparative study of self-reported and expert assessed work-relatedness. Occup Environ Med 2005;62:e32.
20. Wikman A, Marklund S, Alexanderson K. Illness, disease, and sickness absence: an empirical test of differences between concepts of ill health. J Epidemiol Community Health 2005 Jun;59(6):450-4. https://doi.org/10.1136/ jech.2004.025346.

21. Spierenburg EA, Smit LA, Heederik D, Robbe P, Hylkema MN, Wouters IM. Healthy worker survivor analysis in an occupational cohort study of Dutch agricultural workers. Int Arch Occup Environ Health 2015 Nov;88(8):1165-73. https://doi.org/10.1007/s00420-015-1047-9.

22. Susitaival P, Husman L, Hollmén A, Horsmanheimo M. Dermatoses determined in a population of farmers in a questionnaire-based clinical study including methodology validation. Scand J Work Environ Health 1995 Feb;21(1):30 5. https://doi.org/10.5271/sjweh.5.

23. Smit HA, Coenraads PJ, Lavrijsen AP, Nater JP. Evaluation of a self-administered questionnaire on hand dermatitis. Contact Dermat 1992 Jan;26(1):11-6. https://doi. org/10.1111/j.1600-0536.1992.tb00861.x.

24. Susitaival P. (2012). Questionnaire methods in occupational skin disease epidemiology. In Rustemeyer T, Elsner P, John SM, Maidbach HI (Eds). Kanerva's Occupational Dermatology (pp. 1353-1357). Volume 2. Second edition. Berlin: Springer-Verlag.

25. Teschke K, Olshan AF, Daniels JL, De Roos AJ, Parks $\mathrm{CG}$, Schulz $\mathrm{M}$ et al. Occupational exposure assessment in case-control studies: opportunities for improvement. Occup Environ Med 2002 Sep;59(9):575-93. https://doi. org/10.1136/oem.59.9.575.

26. Podsakoff PM, MacKenzie SB, Lee JY, Podsakoff NP. Common method biases in behavioral research: a critical review of the literature and recommended remedies. J Appl Psychol 2003 Oct;88(5):879-903. https://doi. org/10.1037/0021-9010.88.5.879.

Received for publication: 5 November 2018 